Published in final edited form as:

J Reprod Immunol. 2014 June ; 103: 38-44. doi:10.1016/j.jri.2014.01.001.

\title{
Glucose and lipopolysaccharide regulate proatherogenic cytokine release from mononuclear cells in polycystic ovary syndrome
}

\author{
Frank González ${ }^{a}$, John P. Kirwan ${ }^{b}$, Neal S. Rote ${ }^{c}$, Judi Minium ${ }^{c}$, and Valerie B. O’Leary ${ }^{d}$ \\ aDepartment of Obstetrics and Gynecology, Indiana University School of Medicine, Indianapolis, \\ Indiana, U.S.A \\ bepartments of Gastroenterology/Hepatology and PathoBiology, Lerner Research Institute, \\ Cleveland Clinic, Cleveland, Ohio, U.S.A \\ 'Department of Reproductive Biology, Case Western Reserve University School of Medicine, \\ Cleveland, Ohio, U.S.A \\ dHelmholtz Zentrum Munchen, Institute of Radiation Biology, Neuherberg, Germany
}

\begin{abstract}
Women with polycystic ovary syndrome (PCOS) have chronic low-grade inflammation, which can increase the risk of atherogenesis. We examined the effect of glucose ingestion and lipopolysaccharide (LPS) on markers of proatherogenic inflammation in the mononuclear cells (MNC) and plasma of women with PCOS. Sixteen women with PCOS (8 lean, 8 obese) and 15 weight-matched controls ( 8 lean, 7 obese) underwent a 3-h oral glucose tolerance test (OGTT). Interleukin-6 (IL-6) and interleukin-1 $\beta$ (IL-1 $\beta$ ) release from MNC cultured in the presence of LPS and plasma IL-6, C-reactive protein (CRP), and soluble vascular adhesion molecule-1 (sVCAM-1) were measured from blood samples drawn while fasting and $2 \mathrm{~h}$ after glucose ingestion. Truncal fat was measured by dual-energy absorptiometry (DEXA). Lean women with PCOS and obese controls failed to suppress LPS-stimulated IL- 6 and IL- $1 \beta$ release from MNC after glucose ingestion. In contrast, obese women with PCOS suppressed these MNC-derived cytokines under the same conditions. In response to glucose ingestion, plasma IL-6 and sVCAM-1 increased and CRP suppression was attenuated in both PCOS groups and obese controls compared with lean controls. Fasting plasma IL-6 and CRP correlated positively with percentage of truncal fat. The absolute change in plasma IL-6 correlated positively with testosterone. We conclude that glucose ingestion promotes proatherogenic inflammation in PCOS with a systemic response that is independent of obesity. Based on the suppressed MNC-derived cytokine responses suggestive of
\end{abstract}

(C) 2014 Elsevier Ireland Ltd. All rights reserved.

Corresponding author: Frank González, Indiana University School of Medicine, Department of Obstetrics and Gynecology, AOC Room 6046, 550 N. University Boulevard, Indianapolis, Indiana 46202, U.S.A., gonzalef@ iupui.edu, Telephone \#: 1-317-944-4058, Fax \#: 1-317-944-7417.

Conflict of interest: The authors confirm that they have no conflict of interest.

Publisher's Disclaimer: This is a PDF file of an unedited manuscript that has been accepted for publication. As a service to our customers we are providing this early version of the manuscript. The manuscript will undergo copyediting, typesetting, and review of the resulting proof before it is published in its final citable form. Please note that during the production process errors may be discovered which could affect the content, and all legal disclaimers that apply to the journal pertain. 
LPS tolerance, chronic low-grade inflammation may be more profound in obese women with PCOS. Excess abdominal adiposity and hyperandrogenism may contribute to atherogenesis in PCOS.

\section{Keywords}

inflammation; glucose; atherosclerosis; abdominal adiposity; hyperandrogenism

\section{Introduction}

In polycystic ovary syndrome (PCOS), glucose ingestion triggers an inflammatory response that is independent of obesity (González et al., 2005, 2006b, 2012a). Indeed, peripheral blood mononuclear cells (MNC) of lean women with PCOS exhibit increased nuclear factor $\kappa B(N F \kappa B)$ activation following an oral glucose challenge (González et al., 2006b, 2012a). $\mathrm{NF} \times \mathrm{B}$ regulates transcription of a variety of proatherogenic inflammatory mediators that include interleukin-6 (IL-6), interleukin-1 $\beta$ (IL-1 $\beta$ ), and soluble vascular cell adhesion molecule-1 (sVCAM-1). IL- 6 and IL-1 $\beta$ are endocrine cytokines that stimulate synthesis of C-reactive protein (CRP) in the liver (Barnes and Karin, 1997; Moshage et al., 1988). Whereas SVCAM-1 causes attachment of MNC to the vascular endothelium, CRP promotes the uptake of lipids into MNC-derived foamy macrophages within atherosclerotic plaques (Carlos et al., 1991; Zwaka et al., 2001). Positive feedback by IL-6 and IL-1 $\beta$ perpetuates the preceding molecular events (Romano et al., 1997; Wang et al., 1995). Thus, IL-6, IL-1 $\beta$, CRP, and sVCAM-1 work in concert in the development of atherosclerosis.

Lipopolysaccharide (LPS) is a bacterial component capable of activating NFkB in MNC upon binding to toll-like receptor 4 (TLR4), a pathogen pattern recognition receptor implicated in the development of atherosclerosis (Covert et al., 2005; Xu et al., 2001). LPS originating from gut-related bacteria can access the circulation in the presence of nutrients that increase intestinal permeability (Deopurkar et al., 2010; Neyrinck et al., 2008). High circulating LPS activity is associated with components of the metabolic syndrome (Lassenius et al., 2011). In our previous studies on glucose-stimulated inflammation and insulin resistance in PCOS, we evaluated TNFa, the proinflammatory cytokine that is a known mediator of insulin resistance. TNFa release from MNC obtained while fasting is increased in PCOS after direct in vitro exposure to glucose alone (González et al., 2006a) or LPS alone (unpublished results), indicating that MNC in the disorder are already preactivated. Furthermore, the TNFa response from MNC is altered in PCOS when hyperglycemia is followed in tandem by in vitro LPS exposure. This alteration is characterized in lean women with PCOS by a failure to elicit the normal suppression of TNFa release from MNC that occurs in an uninflamed population, and in obese women with PCOS by paradoxical TNFa suppression akin to a phenomenon known as LPS tolerance (González et al., 2005; Ziegler-Heitbrock, 2001). To our knowledge, the hyperglycemic and LPS-related responses of MNC-derived proatherogenic cytokines such as IL-6 and IL-1 $\beta$ have never been explored in women with PCOS.

We examined the effect of glucose ingestion on IL- 6 and IL- $1 \beta$ release from MNC exposed in vitro to LPS, as well as the effect of glucose ingestion alone on circulating IL-6, CRP, and 
sVCAM-1 in women with PCOS. We hypothesized that in response to glucose ingestion, LPS-stimulated IL- 6 and IL- $1 \beta$ release from MNC and plasma IL-6, CRP, and sVCAM-1 are altered in women with PCOS compared with weight-matched controls and that these markers of atherogenesis are related to abdominal adiposity, insulin sensitivity, and circulating androgens.

\section{Methods}

\subsection{Subjects}

Sixteen women with PCOS ( 8 lean and 8 obese) 20-34 years of age and 15 weight-matched control subjects ( 8 lean and 7 obese) 20-39 years of age volunteered for study participation. Some subjects in the current study had been involved in our previous work on PCOS and insulin resistance (González et al., 2006b). The women with PCOS were selected using NIH criteria because this particular PCOS phenotype is most associated with metabolic dysfunction (Wild et al., 2010). All control subjects had regular menses lasting 25 to 35 days and a luteal range serum progesterone level consistent with ovulation $(>5 \mathrm{ng} / \mathrm{ml})$. All control subjects exhibited normal circulating androgen levels and did not have any skin manifestations of androgen excess or polycystic ovaries on ultrasound.

Diabetes and inflammatory illnesses were excluded in all subjects. None of them smoked tobacco or used medications that could have an impact on carbohydrate metabolism or immune function for a minimum of 6 weeks before beginning the study. None of the subjects exercised regularly during the 6 months before study participation. Written informed consent was obtained in all subjects according to Institutional Review Board guidelines for the protection of human subjects.

\subsection{Study Design}

All subjects ingested a 75-g glucose beverage after an overnight fast of $\sim 12 \mathrm{~h}$. Blood samples were drawn at $0,30,60,90$, and $120 \mathrm{~min}$ for glucose and insulin determination. Additional plasma was isolated from the fasting and 120-min (2-h) blood samples and stored at $-80^{\circ} \mathrm{C}$ until assayed for IL-6, CRP, and sVCAM- 1 . The early glucose response was determined by calculating the area under the curve during the first $30 \mathrm{~min}$ of the OGTT (AUC $_{0-30}$ glucose) using the trapezoidal method. Insulin sensitivity was derived from the

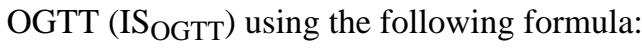

$10,000$ divided by the square root of (fasting glucose $\times$ fasting insulin $) \times($ mean glucose $\times$ mean insulin $)$

(Matsuda and DeFronzo, 1999). Dual-energy absorptiometry (DEXA) was used to determine the percentage of total body fat and the percentage of truncal fat (Hologic Inc., Waltham, MA, USA), as previously described (González et al., 2005).

Isolation and culture of MNC were performed as previously described (González et al., 2005). MNC were incubated for $24 \mathrm{~h}$ with $1 \mathrm{ng} / \mathrm{ml}$ of LPS endotoxin from Escherichia coli 0127:B8 (Sigma-Aldrich Co. LLC, St. Louis, MO, USA). Culture supernatants were collected and stored at $-80^{\circ} \mathrm{C}$ until assayed for IL- 6 and IL-1 $\beta$.

Plasma glucose, insulin, IL-6, and CRP concentrations along with those of IL-6 and IL-1 $\beta$ in MNC culture supernatants were measured as previously described (González et al., 2005, 
2006a). Serum luteinizing hormone (LH), testosterone, androstenedione, and dehydroepiandrosterone-sulfate (DHEA-S) were also measured as previously described (González et al., 2005, 2007). Plasma sVCAM-1 was measured by ELISA (R\&D Systems, Minneapolis, MN, USA). All samples were measured in duplicate in the same assay. The interassay and intra-assay coefficients of variation for all assays were $7 \%$ and $12 \%$ respectively.

\subsection{Statistics}

Data were analyzed using StatV2iew (SAS Institute, Cary, NC, USA). All values were initially examined graphically for departure from normality, and the natural logarithm transformation was applied as needed. Descriptive data and change from baseline of variables were compared between groups using ANOVA for multiple group comparisons. The source of significance by ANOVA was identified using Tukey's post hoc test. Paired Student's t-tests were performed for within-group comparisons. Treatment effects of glucose ingestion were determined by calculating the absolute change in proatherogenic inflammation markers for each participant in view of interindividual variability. In the case of plasma CRP, the percentage change was calculated owing to the large magnitude of difference in values between lean and obese subjects. The Spearman rank correlation coefficient was used to estimate the correlation between parameters. Data are presented as mean \pm SE, and results with a two-tailed a-level of 0.05 were considered significant.

\section{Results}

\subsection{Age, Body Composition, Blood Pressure, and Lipids}

All four groups were similar in age and height (Table 1). Weight, body mass index (BMI), percentage of total body fat, percentage of truncal fat, and waist circumference were significantly $(\mathrm{p}<0.04)$ greater in obese subjects than in those who were lean irrespective of whether or not they had PCOS, but were similar when women with PCOS were compared with weight-matched controls.

Systolic blood pressure was similar among groups. Diastolic blood pressure was significantly $(\mathrm{p}<0.03)$ higher in women with PCOS regardless of weight class compared with lean controls, but mean values were within the normotensive range. The levels of total cholesterol, high and low density lipoprotein cholesterol, and triglycerides were similar among groups.

\subsection{Plasma Hormone Levels, Glycemic Status, and Insulin Sensitivity}

Circulating levels of LH, testosterone, androstenedione, and DHEA-S were significantly $(p<0.05)$ elevated in women with PCOS compared with control subjects regardless of weight class (Table 1).

Glucose levels while fasting and $2 \mathrm{~h}$ post-glucose ingestion along with $\mathrm{AUC}_{0-30}$ glucose were similar in women with PCOS and controls independent of body mass (Table 1). All subjects had a normal glucose response during the OGTT, with fasting glucose levels <100 $\mathrm{mg} / \mathrm{dl}$ and 2-h glucose levels ranging between 70 and $136 \mathrm{mg} / \mathrm{dl}$. Fasting insulin levels were 
significantly higher $(\mathrm{p}<0.05)$ in obese women with PCOS compared with lean women with PCOS and both control groups and in obese controls compared with lean controls. The IS OGTT was significantly higher $(\mathrm{p}<0.02)$ in obese subjects regardless of PCOS status compared with lean controls and in lean women with PCOS compared with lean controls.

\subsection{IL-6 and IL-1 $\beta$ Release from MNC}

Lipopolysaccharide-stimulated IL-6 and IL- $1 \beta$ release from MNC in the fasting state was similar in all four groups (data not shown). Glucose ingestion significantly $(\mathrm{p}<0.03)$ suppressed LPS-stimulated IL-6 release from MNC of lean controls and obese women with PCOS (Fig. 1A) and LPS-stimulated IL-1 $\beta$ release from MNC of lean controls (Fig. 1B). However, LPS-stimulated IL- 6 and IL- $1 \beta$ release remained unaltered in obese controls and lean women with PCOS. The absolute change in LPS-stimulated IL- 6 and IL- $1 \beta$ release in obese controls was significantly different $(\mathrm{p}<0.002)$ from that in lean controls. There was also a significant difference $(\mathrm{p}<0.02)$ between the diametrically opposite IL- 6 and IL- $1 \beta$ responses of obese and lean women with PCOS.

\subsection{Plasma IL-6, CRP, and SVCAM-1}

Fasting plasma IL-6 and CRP were significantly $(\mathrm{p}<0.03)$ higher in obese subjects irrespective of whether or not they had PCOS compared with lean controls (Table 1). Obese subjects, regardless of PCOS status, also exhibited modestly higher fasting plasma IL-6 levels and significantly $(p<0.03)$ higher fasting CRP levels compared with lean women with PCOS. Fasting CRP was 5-fold higher in lean women with PCOS compared with lean controls, but did not achieve statistical significance. Fasting IL-6 and CRP were similar in obese women with PCOS to those in obese controls and similar in lean women with PCOS to those in lean controls. Fasting sVCAM-1 was similar in all four groups.

In response to glucose ingestion, plasma IL-6, CRP, and sVCAM-1 significantly $(\mathrm{p}<0.05)$ decreased in lean controls (Fig. 2A, B). Plasma IL-6 and sVCAM-1 significantly ( $\mathrm{p}<0.05)$ increased in both PCOS groups and obese controls, whereas plasma CRP significantly $(\mathrm{p}<0.05)$ decreased in lean controls and obese subjects regardless of PCOS status (Fig. 2C). The change in plasma IL-6, sVCAM-1, and CRP were similar in both PCOS groups and obese controls. Compared with lean controls, the change in plasma IL-6 and SVCAM-1 was significantly $(\mathrm{p}<0.05)$ greater and the change in CRP was significantly $(\mathrm{p}<0.05)$ lower in both PCOS groups and obese controls.

\subsection{Correlations}

There was a negative correlation between IS $_{\text {OGTT }}$ and BMI $(r=-0.57, p<0.002)$, percentage of body fat $(\mathrm{r}=-0.52, \mathrm{p}<0.02)$, percentage of truncal fat $(\mathrm{r}=-0.56, \mathrm{p}<0.003)$, and waist circumference $(r=-0.50, p<0.02)$ for the combined groups. The change in MNC-derived cytokine release in response to glucose ingestion also correlated negatively with the percentage of body fat (IL-6, $r=-0.70, p<0.009$; IL-1 $\beta, r=-0.67, p<0.04)$ and the percentage of truncal fat (IL-6, $r=-0.70, p<0.007$; IL-1 $\beta, r=-0.50, p<0.05)$ in women with PCOS. In contrast, the MNC-derived cytokine response correlated positively with the percentage of body fat (IL-6, r=0.63, $\mathrm{p}<0.02$; IL-1 $\beta, \mathrm{r}=0.60, \mathrm{p}<0.04)$ and the percentage of truncal fat (IL-6, $r=0.59, \mathrm{p}<0.03$; IL-1 $\beta, \mathrm{r}=0.67, \mathrm{p}<0.02)$ in control subjects. 
IS $_{\text {OGTT }}$ correlated positively with the MNC-derived IL- $1 \beta$ response $(r=0.51, p<0.05)$ and the plasma IL-6 response $(r=0.53, p<0.05)$ in women with PCOS and negatively with the MNC-derived IL- $1 \beta$ response $(r=0.61, p<0.03)$ in control subjects. Fasting plasma cytokines correlated positively with the percentage of body fat (IL-6, $r=0.55, \mathrm{p}<0.05$; CRP, $r=0.87$, $\mathrm{p}<0.001)$ and the percentage of truncal fat (IL-6, $r=0.56, \mathrm{p}<0.04$; CRP, $r=0.88, \mathrm{p}<0.0006)$ in women with PCOS.

The change in MNC-derived IL-6 release in response to glucose ingestion correlated positively with that of IL- $1 \beta$ for the combined groups $(r=0.79, p<0.0001)$ and separately in women with PCOS $(r=0.80, p<0.003)$ and controls subjects $(r=0.83, p<0.04)$. The change in plasma IL-6 correlated positively with testosterone $(r=0.36, p<0.05)$ for the combined groups. There was also a positive correlation between the MNC-derived IL-6 response and $\mathrm{LH}(\mathrm{r}=0.50, \mathrm{p}<0.05)$ and between the plasma sVCAM- 1 response and testosterone $(\mathrm{r}=0.60$, $\mathrm{p}<0.04)$ in women with PCOS.

\section{Discussion}

Our data clearly show for the first time that in PCOS, physiological hyperglycemia alters LPS-stimulated proatherogenic cytokine release from MNC. Glucose ingestion followed in tandem by in vitro LPS exposure causes impairment of the normal suppressive response of IL-6 and IL-1 $\beta$ in lean women with PCOS. The paradoxical suppression of these cytokines in obese women with PCOS under the same conditions is suggestive of LPS tolerance. Glucose ingestion alone causes elevations in circulating IL-6 and sVCAM- 1 and attenuated suppression of plasma CRP in lean women with PCOS compared with lean controls consistent with systemic induction of proatherogenic inflammation that is independent of obesity. There are also independent associations of proatherogenic inflammation markers in MNC and plasma with measures of adiposity and testosterone. Thus, excess adipose tissue, especially of abdominal origin, and hyperandrogenism may be involved in perpetuating a proatherogenic milieu in women with PCOS at an early age.

Suppression of proatherogenic inflammation appears to be the normal in vivo response to physiological hyperglycemia. LPS-stimulated IL- 6 and IL- $1 \beta$ release from MNC and plasma IL-6, CRP, and sVCAM-1 all decrease in response to glucose ingestion in lean controls. This is consistent with our previous reports for TNFa as well as IL-6 and IL- $1 \beta$ in lean healthy young men and women (González et al., 2005, 2007; Kirwan et al., 2001). These observations in lean controls are important because the collective effects of IL-6, IL-1 $\beta$, CRP and sVCAM-1 are responsible for MNC adhesion to the vascular endothelium and lipid phagocytosis by MNC-derived foamy macrophages within atherosclerotic plaques. Thus, suppression of proatherogenic inflammation during postprandial hyperglycemia may serve to preserve blood vessel integrity by limiting the development of atherosclerosis.

Lean women with PCOS may be at an increased risk of accelerated atherogenesis. IL-6 and IL- $1 \beta$ release from MNC remains unaltered in this group in response to glucose ingestion followed by in vitro LPS exposure compared with the decline observed in lean controls. These results mimic our previous findings for TNFa in lean women with PCOS after the same maneuver (González et al., 2005). Lean women with PCOS also exhibit frank 
increases in plasma IL-6 and sVCAM- 1 and attenuated plasma CRP suppression in response to glucose ingestion alone compared with lean controls. MNC preactivation, as observed in obesity (Ghanim et al., 2004), may account for these proinflammatory responses as demonstrated by the increased TNFa release from MNC in the fasting state after direct in vitro exposure to glucose alone (González et al., 2006a) or LPS alone (unpublished results) in women with PCOS. Indeed, obese controls exhibit nearly identical responses to glucose ingestion. Lean women with PCOS and obese controls also exhibit fasting CRP elevations despite the difference in magnitude as previously documented along with a similar degree of

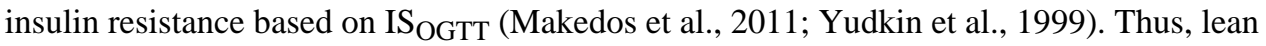
women with PCOS demonstrate a unique proatherogenic risk profile that is exacerbated by glucose ingestion and is somewhat similar to that of obese women without PCOS.

Obese women with PCOS may be at an even greater risk of developing atherosclerosis. Paradoxical suppression of LPS-stimulated cytokine release from MNC in response to glucose ingestion followed by in vitro LPS exposure is evident in obese women with PCOS. This is suggestive of LPS tolerance of intensely preactivated MNC (West and Heagy, 2002; Ziegler-Heitbrock, 2001). In contrast, the pronounced plasma proatherogenic inflammation marker response to glucose ingestion alone in obese women with PCOS is similar to that of lean women with PCOS and obese controls. Our findings highlight the spectrum of inflammatory response that occurs in relation to the degree of inflammation present in PCOS. Inflammation is upregulated during an acute response to a proinflammatory stimulus, but is downregulated in the presence of more profound chronic inflammation in response to repetitive stimulation involving LPS (West and Heagy, 2002). LPS tolerance typically occurs as a survival mechanism in healthy individuals during the late stages of sepsis (Ertel et al., 1995). However, this phenomenon also occurs in other chronic inflammatory states, such as surgical recovery and normal pregnancy, and is highly reproducible in vitro (Lemaire et al., 1998; van Nieuwenhoven et al., 2003; West and Heagy, 2002). Inhibition of $\mathrm{NFKB}$ activation is a key event in the mechanism of LPS tolerance (West and Heagy, 2002; Ziegler-Heitbrock, 2001). Further investigation is merited to determine whether there is decreased NFKB activation in nutrient-stimulated, LPS-exposed MNC of obese women with PCOS to support the concept that the suppressed MNC-derived cytokine response is due to LPS tolerance. Obese women with PCOS are also the most insulin resistant, which is consistent with a more severe proatherogenic risk profile (Freeman et al., 2003). This is corroborated by the direct relationship between the glucose-stimulated plasma IL- 6 response and insulin sensitivity. Thus, the combined inflammatory loads of PCOS and obesity may confer a greater degree of chronic low-grade inflammation that could translate into greater atherogenesis.

In PCOS, excess adiposity when present may be a major contributor to proatherogenic inflammation. Measures of adiposity, including abdominal adiposity, are directly related to the MNC-derived IL- 6 and IL-1 $\beta$ responses in control subjects and to fasting plasma IL-6 and CRP in women with PCOS. The paradoxical MNC-derived cytokine responses that are inversely related to measures of adiposity and directly related to insulin sensitivity in women with PCOS reflect the suppressed LPS-tolerant cytokine release in obese women with the disorder. Although not evident in the present study, almost one-third of lean women with 
PCOS have excess abdominal adiposity (Carmina et al., 2007; González et al., 2012a).

Roughly half of the IL- 6 in the expanded adipose mass of obese individuals is produced by MNC-derived macrophages (Weisberg et al., 2003). Insulin sensitivity is also inversely related to abdominal adiposity. Thus, inflamed adipose tissue of women with PCOS, including in the abdomen, may perpetuate the aberrant proatherogenic response to glucose ingestion observed in MNC and the circulation.

In PCOS, hyperandrogenism may also promote proatherogenic inflammation. LH is directly related to the MNC-derived IL-6 response. Testosterone is directly related to the plasma sVCAM-1 response in women with PCOS and to the plasma IL-6 response for the combined groups. We have previously reported similar associations between androgens and measures of inflammation (González et al., 2006a, 2006b, 2012a). The association with LH suggests that pituitary LH hypersecretion in PCOS might contribute to the promotion of proatherogenic inflammation. Nevertheless, direct androgen exposure in vitro increases sVCAM-1 expression in endothelial cells and LDL oxidation in MNC-derived macrophages (McCrohon et al., 1999; Zhu et al., 1997). Androgens have been shown to upregulate the $\mathrm{NF \kappa B}$ inflammation pathway in MNC in a receptor-mediated fashion (Ashcroft and Mills, 2002; Ripple et al., 1999). Most importantly, induction of hyperandrogenism in normal reproductive-age women activates MNC and increases MNC sensitivity to glucose ingestion (González et al., 2012b). Thus, hyperandrogenism in PCOS may promote the transcription of proatherogenic inflammation mediators from glucose-stimulated MNC to increase the risk of atherosclerotic plaque formation.

In conclusion, proatherogenic inflammation markers are altered in PCOS in response to glucose ingestion. Lean women with PCOS exhibit failed suppression of LPS-stimulated IL- 6 and IL- $1 \beta$ release from MNC that is similar to that in obese controls. In contrast, obese women with PCOS exhibit suppression of these MNC-derived cytokines under the same conditions. This latter phenomenon is suggestive of LPS tolerance and may reflect a greater degree of chronic low-grade inflammation. Furthermore, women with PCOS exhibit increased plasma IL-6 and sVCAM-1 and attenuated suppression of plasma CRP following glucose ingestion alone that is independent of obesity and reflective of systemic proatherogenic inflammation. The relationship between these markers and abdominal fat and testosterone provides evidence that in PCOS, excess abdominal adiposity and hyperandrogenism may contribute to the promotion of atherosclerosis.

\section{Acknowledgments}

This research was supported by grant HD-048535 to F.G. from the National Institutes of Health.

\section{References}

Ashcroft GS, Mills SL. Androgen receptor-mediated inhibition of cutaneous wound healing. J Clin Invest. 2002; 110:615-624. [PubMed: 12208862]

Barnes PJ, Karin M. Nuclear factor- $\kappa$ B: pivitol transcription factor in chronic inflammatory diseases. N Engl J Med. 1997; 336:1066-1071. [PubMed: 9091804]

Carlos T, Kovach N, Schwartz B, Rosa M, Newman B, Wayner E, et al. Human monocytes bind to two cytokine-induced adhesive ligands on cultured human endothelial cells: endothelial-leukocyte 
adhesion molecule-1 and vascular cell adhesion molecule-1. Blood. 1991; 77:2266-2271. [PubMed: 1709380]

Carmina E, Bucchierri S, Esposito A, Del Puente A, Mansueto P, Orio F, et al. Abdominal fat quantity and distribution in women with polycystic ovary syndrome and extent of its relation to insulin resistance. J Clin Endocrinol Metab. 2007; 92:2500-2505. [PubMed: 17405838]

Covert MW, Leung TH, Gaston JE, Baltimore D. Achieving stability of lipopolysaccharide-induced NF-kappaB activation. Science. 2005; 309:1854-1857. [PubMed: 16166516]

Deopurkar R, Ghanim H, Friedman J, Abuaysheh S, Sia CL, Mohanty P, et al. Differential effects of cream, glucose, and orange juice on inflammation, endotoxin, and the expression of toll-like receptor-4 and suppressor of cytokine signaling-3. Diabetes Care. 2010; 33:991-997. [PubMed: 20067961]

Ertel W, Kremer JP, Kenney J, Steckholzer U, Jarrar D, Trentz O, et al. Downregulation of proinflammatory cytokine release in whole blood from septic patients. Blood. 1995; 85:1341-1347. [PubMed: 7858264]

Freeman MS, Mansfield MW, Barrett JH, Grant PJ. Insulin resistance: an atherothrombotic syndrome. The Leeds family study. Thromb Haemost. 2003; 89:161-168. [PubMed: 12540966]

Ghanim H, Aljada A, Hofmeyer D, Syed T, Mohanty P, Dandona P. Circulating mononuclear cells in the obese are in a proinflammatory state. Circulation. 2004; 110:1564-1571. [PubMed: 15364812]

González F, Rote NS, Minium J, Kirwan JP. Hyperglycemia alters tumor necrosis factor-a release from mononuclear cells in women with polycystic ovary syndrome. J Clin Endocrinol Metab. 2005; 90:5336-5342. [PubMed: 15985479]

González F, Rote NS, Minium J, Kirwan JP. In vitro evidence that hyperglycemia stimulates tumor necrosis factor-a release in obese women with polycystic ovary syndrome. J Endocrinol. 2006a; 88:521-529. [PubMed: 16522732]

González F, Rote NS, Minium J, Kirwan JP. Increased activation of nuclear factor $\kappa \mathrm{B}$ triggers inflammation and insulin resistance in polycystic ovary syndrome. J Clin Endocrinol Metab. 2006b; 91:1508-1512. [PubMed: 16464947]

González F, Rote NS, Minium J, O’Leary VB, Kirwan JP. Obese reproductive age women exhibit a proatherogenic inflammatory response during hyperglycemia. Obesity. 2007; 15:2436-2444. [PubMed: 17925469]

González F, Sia CL, Shepard MK, Rote NS, Minium J. Inflammation in response to glucose ingestion is independent of excess abdominal adiposity in normal weight women with polycystic ovary syndrome. J Clin Endocrinol Metab. 2012a; 97:4071-4079. [PubMed: 22904174]

González F, Nair KS, Daniels JK, Basal E, Schimke JM. Hyperandrogenism sensitizes mononuclear cells to promote glucose-induced inflammation in lean reproductive-age women. Am J Physiol Endocrinol Metab. 2012b; 302:E297-E306. [PubMed: 22045316]

Kirwan JP, Krishnan RK, Weaver JA, Del Aguila LF, Evans WJ. Human aging is associated with altered TNF-a production during hyperglycemia and hyperinsulinemia. Am J Physiol Endocrinol Metab. 2001; 281:E1137-E1143. [PubMed: 11701426]

Lassenius MI, Pietiläinen KH, Kaartinen K, Pussinen PJ, Syrjänen J, Forsblom C, et al. FinnDiane Study Group. Bacterial endotoxin activity in human serum is associated with dyslipidemia, insulin resistance, obesity, and chronic inflammation. Diabetes Care. 2011; 34:1809-1815. [PubMed: 21636801]

Lemaire LC, van der Poll T, van Lanschot JJB, Endert E, Buurman WA, van Deventer SJ. Minimal invasive surgery induces endotoxin-tolerance in the absence of detectable endotoxemia. J Clin Immunol. 1998; 18:414-420. [PubMed: 9857286]

Makedos A, Goulis DG, Arvanitidou M, Mintziori G, Papanikolaou A, Makedou A, et al. Increased serum C-reactive protein levels in normal weight women with polycystic ovary syndrome. Hippokratia. 2011; 15:323-326. [PubMed: 24391413]

Matsuda M, DeFronzo R. Insulin sensitivity indices obtained from oral glucose tolerance testing. Diabetes Care. 1999; 22:1462-1470. [PubMed: 10480510]

McCrohon JA, Jessup W, Handelsman DJ, Celermajer DS. Androgen exposure increases human monocyte adhesion to vascular endothelium and endothelial cell expression of vascular adhesion molecule-1. Circulation. 1999; 99:2317-2322. [PubMed: 10226099] 
Moshage HJ, Roelofs HM, van Pelt JF, Hazenberg BP, van Leeuwen MA, Limburg PC, et al. The effect of interleukin-1, interleukin- 6 and its interrelationship on the synthesis of serum amyloid A and C-reactive protein in primary cultures of adult human hepatocytes. Biochem Biophys Res Commun. 1988; 155:112-117. [PubMed: 3261980]

Neyrinck AM, Delzenne NM, Burcelin R. Changes in gut microbiota control metabolic endotoxemiainduced inflammation in high-fat diet-induced obesity and diabetes in mice. Diabetes. 2008; 57:1470-1481. [PubMed: 18305141]

Ripple MO, Henry WF, Schwarze SR, Wilding W, Weindruch R. Effects of anti-oxidants on androgen-induced AP-1 and NF- $\kappa$ B DNA-binding activity in prostate carcinoma cells. J Natl Cancer Inst. 1999; 14:1227-1232. [PubMed: 10413424]

Romano M, Sironi M, Toniatti C, Polentarutti N, Fruscella P, Ghezzi P, et al. Role of IL-6 and its soluble receptor in induction of chemokines and leukocyte recruitment. Immunity. 1997; 6:315325. [PubMed: 9075932]

van Nieuwenhoven ALV, Bouman A, Moes H, Heineman MJ, de Leij LFMH, Santema J, et al. Endotoxin-induced cytokine production of monocytes of third-trimester pregnant women compared with women in the follicular phase of the menstrual cycle. Obstet Gynecol. 2003; 188:1073-1077.

Wang X, Feuerstein GZ, Gu JL, Lysko PG, Yue TL. Interleukin-1 beta induces expression of adhesion molecules in human vascular smooth muscle cells and enhances adhesion of leukocytes to smooth muscle cells. Atherosclerosis. 1995; 115:89-98. [PubMed: 7545398]

Weisberg SP, McCann D, Desai M, Rosenbaum M, Leibel RL, Ferrante AW Jr. Obesity is associated with macrophage accumulation in adipose tissue. J Clin Invest. 2003; 112:1796-1808. [PubMed: 14679176]

West MA, Heagy W. Endotoxin tolerance: a review. Critical Care Med Suppl. 2002; 30:S64-S73.

Wild RA, Carmina E, Diamanti-Kandarakis E, Dokras A, Escobar-Morreale HF, Futterweit W, et al. Assessment of cardiovascular risk and prevention of cardiovascular disease in women with the polycystic ovary syndrome: a consensus statement by the Androgen Excess and Polycystic Ovary Syndrome (AE-PCOS) Society. J Clin Endocrinol Metab. 2010; 95:2038-2049. [PubMed: 20375205]

Xu XH, Shah PK, Faure E, Equils O, Thomas L, Fishbein MC, et al. Toll-like receptor-4 is expressed by macrophages in murine and human lipid-rich atherosclerotic plaques and upregulated by oxidized LDL. Circulation. 2001; 104:3103-3108. [PubMed: 11748108]

Yudkin JS, Stehouwer CD, Emeis JJ, Coppack SW. C-reactive protein in healthy subjects: associations with obesity, insulin resistance, and endothelial dysfunction: a potential role for cytokines originating from adipose tissue? Arterioscler Thromb Vasc Biol. 1999; 19:972-978. [PubMed: 10195925]

Zhu XD, Bonet B, Knopp RH. 17 $\beta$-Estradiol, progesterone and testosterone inversely modulate lowdensity lipoprotein oxidation and cytotoxity in cultured placental trophoblast and macrophages. Am J Obstet Gynecol. 1997; 177:196-209. [PubMed: 9240607]

Ziegler-Heitbrock L. The p50-homodimer mechanism in tolerance to LPS. J Endotoxin Res. 2001; 7:219-222. [PubMed: 11581573]

Zwaka TP, Hombach V, Torzewski J. C-reactive protein-mediated low density lipoprotein uptake by macrophages: implications for atherosclerosis. Circulation. 2001; 103:1194-1197. [PubMed: 11238260] 

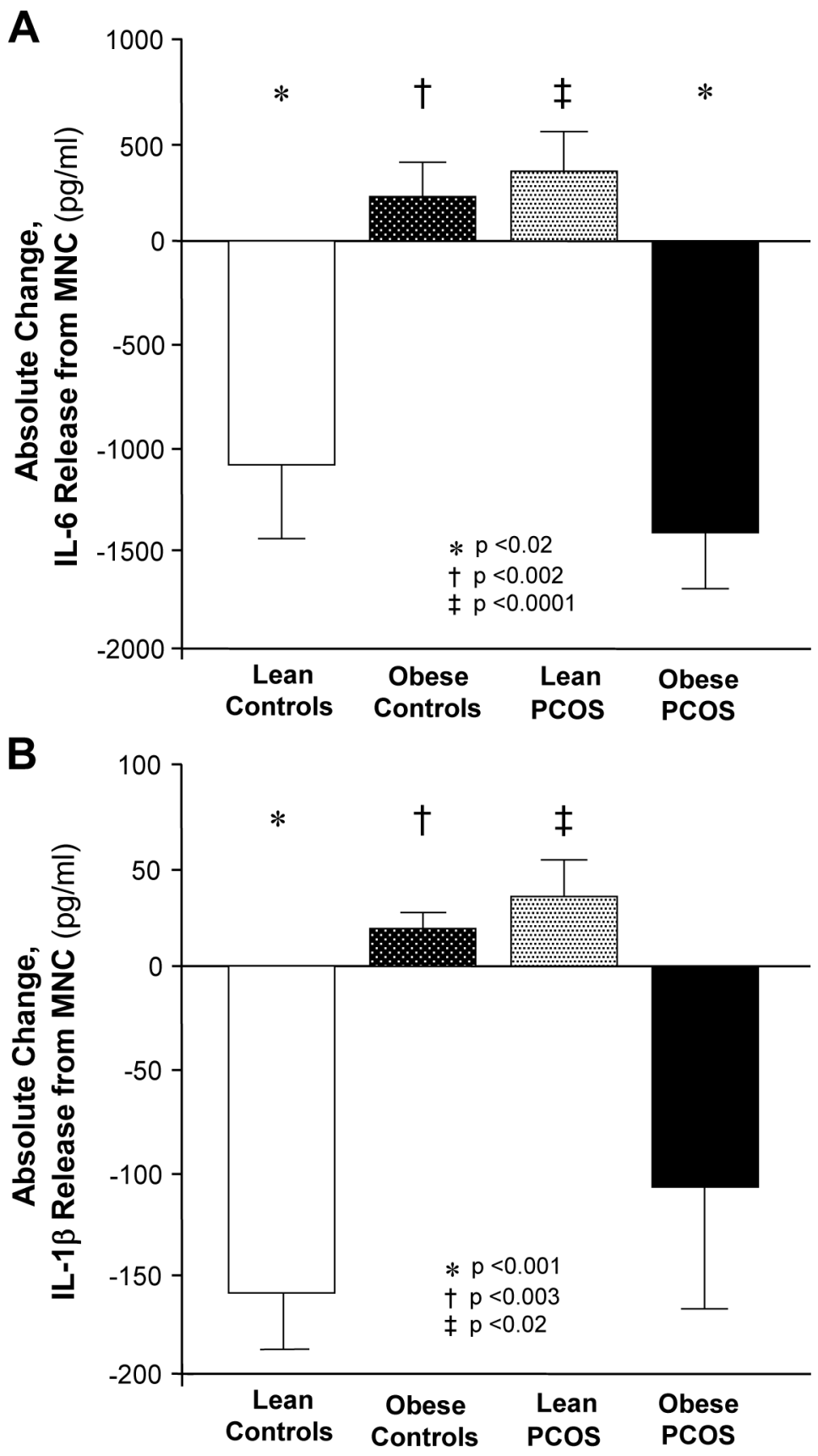

Figure 1.

Absolute change in (A) interleukin-6 (IL-6) and (B) interleukin-1 $\beta$ (IL-1 $\beta$ ) release from mononuclear cells (MNC) cultured with lipopolysaccharide (LPS) for $24 \mathrm{~h}$ when fasting samples (pre) were compared with the samples collected 120 min after glucose ingestion (post). * Post was significantly lower than pre in lean controls for IL-6 $(\mathrm{p}<0.02)$ and IL-1 $\beta$ $(\mathrm{p}<0.001)$ and in obese women with PCOS for IL-6 ( $<<0.02) . \dagger$ Response to glucose ingestion in lean controls was significantly different from that in obese controls for IL-6 $(\mathrm{p}<0.002)$ and IL-1 $\beta(\mathrm{p}<0.003) . \ddagger$ Response to glucose ingestion in lean women with 
polycystic ovary syndrome (PCOS) was significantly different from that in obese women with PCOS for IL-6 $(p<0.0001)$ and IL-1 $\beta(p<0.02)$ 
A

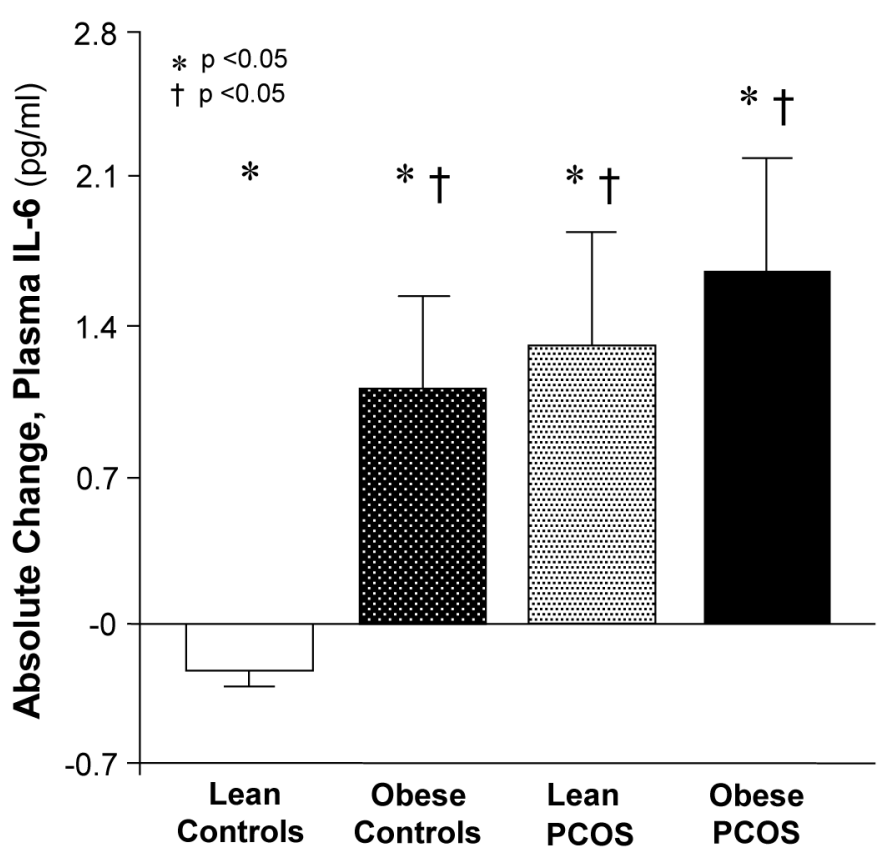

B

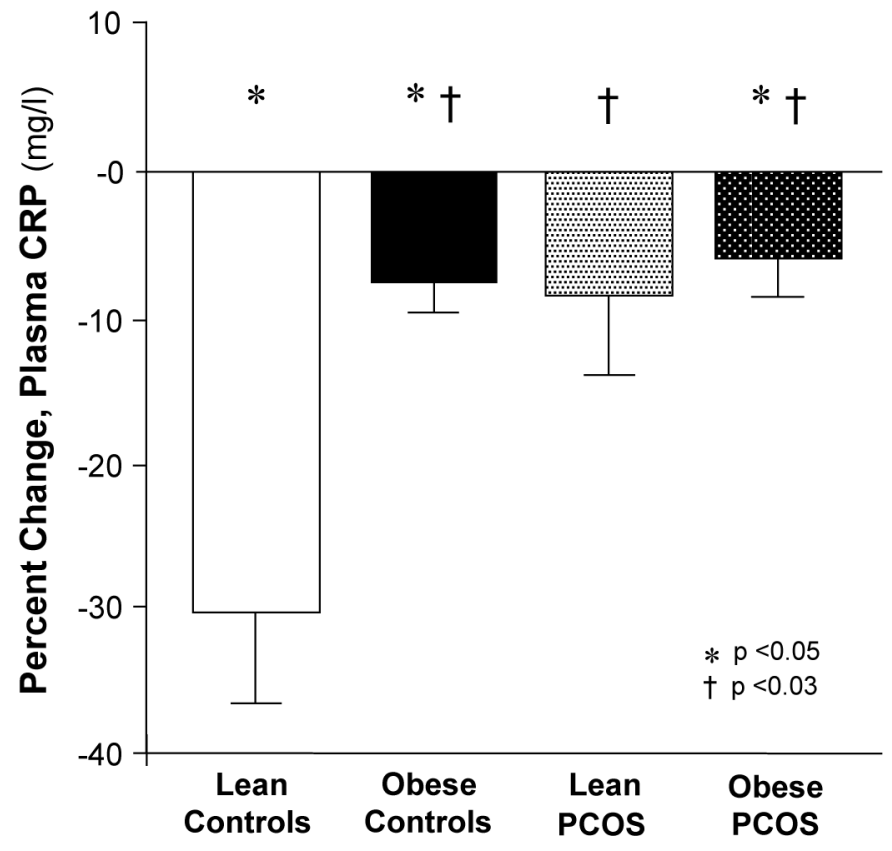




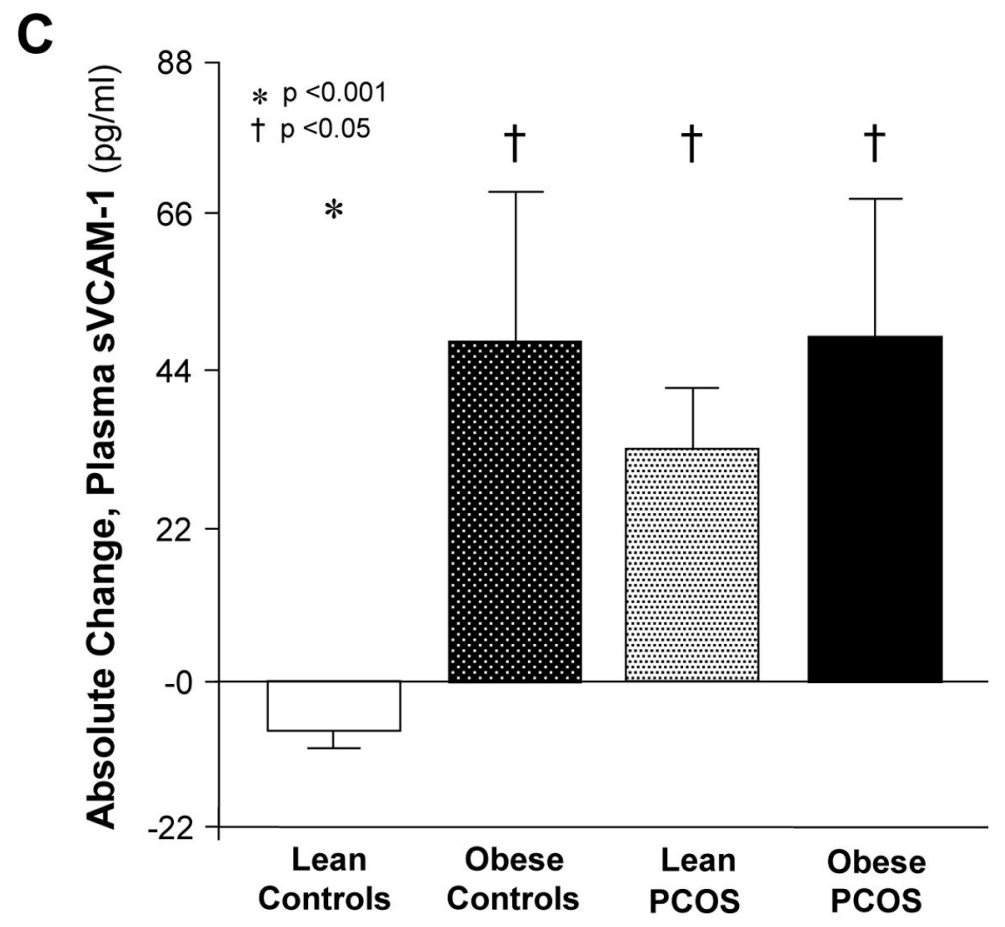

Figure 2.

(A) Absolute change in plasma IL-6, (B) percentage change in plasma C-reactive protein (CRP) and (C) absolute change in plasma soluble vascular adhesion molecule-1 (sVCAM-1) when fasting samples (pre) were compared with the samples collected 120 min after glucose ingestion (post). * Post was significantly lower than pre in lean controls for IL-6, CRP, and sVCAM-1 and in obese controls and obese women with PCOS for CRP; and was significantly higher than pre in obese controls and both PCOS groups for IL-6 and sVCAM-1 ( $\mathrm{p}<0.05)$. $\dagger$ Response to glucose ingestion in obese controls and both PCOS groups was significantly different from that in lean controls for IL-6 and sVCAM-1 ( $<<0.05)$ and CRP $(\mathrm{p}<0.03)$. 


\section{Table 1}

Age, body composition, blood pressure, endocrine, and metabolic parameters and fasting circulating inflammation markers of subjects.

\begin{tabular}{|c|c|c|c|c|}
\hline & \multicolumn{2}{|c|}{ CONTROLS } & \multicolumn{2}{|c|}{ PCOS } \\
\hline & Lean $(n=8)$ & Obese $(n=7)$ & Lean $(n=8)$ & Obese $(n=8)$ \\
\hline Age, years & $29 \pm 2$ & $29 \pm 3$ & $27 \pm 2$ & $27 \pm 2$ \\
\hline Height, cm & $162.8 \pm 1.7$ & $162.6 \pm 2.7$ & $162.9 \pm 3.6$ & $164.4 \pm 2.0$ \\
\hline Body weight, $\mathrm{kg}$ & $58.0 \pm 1.9$ & $92.1 \pm 4.0^{* * *}$ & $61.1 \pm 2.5$ & $95.7 \pm 3.2^{* * *}, \S$ \\
\hline Body mass index, $\mathrm{kg} / \mathrm{m}^{2}$ & $21.9 \pm 0.6$ & $34.8 \pm 1.2^{* * *}$ & $23.1 \pm 0.8$ & $35.4 \pm 1.0^{* * *, \S}$ \\
\hline Total body fat, $\%$ & $32.2 \pm 2.5$ & $42.2 \pm 1.1^{* * *}$ & $30.6 \pm 2.3$ & $42.8 \pm 1.0^{* * *, \S}$ \\
\hline Truncal fat, $\%$ & $30.1 \pm 3.0$ & $42.1 \pm 1.0^{* * * *}$ & $29.3 \pm 2.8$ & $44.1 \pm 1.0^{* * *}, \S$ \\
\hline Waist circumference, $\mathrm{cm}$ & $70.3 \pm 3.1$ & $101.6 \pm 3.5^{* * * *}$ & $74.6 \pm 2.0$ & $98.7 \pm 6.1^{* * *}, \S$ \\
\hline Systolic blood pressure, $\mathrm{mmHg}$ & $106 \pm 3$ & $118 \pm 6$ & $110 \pm 3$ & $122 \pm 6$ \\
\hline Diastolic blood pressure, $\mathrm{mmHg}$ & $56 \pm 3$ & $76 \pm 4^{*}$ & $68 \pm 4^{\dagger}$ & $76 \pm 5^{* * * *}$ \\
\hline Total cholesterol, mg/dl & $163 \pm 6$ & $201 \pm 23$ & $180 \pm 11$ & $188 \pm 11$ \\
\hline Triglycerides, mg/dl & $56 \pm 5$ & $121 \pm 44$ & $88 \pm 3$ & $102 \pm 22$ \\
\hline $\mathrm{HDL}$ - cholesterol, mg/dl & $50 \pm 3$ & $50 \pm 3$ & $52 \pm 5$ & $48 \pm 4$ \\
\hline LDL - cholesterol, mg/dl & $106 \pm 6$ & $121 \pm 19$ & $115 \pm 8$ & $124 \pm 11$ \\
\hline $\mathrm{LH}, \mathrm{mIU} / \mathrm{ml}$ & $2.9 \pm 0.5$ & $2.6 \pm 0.4^{* *}$, & $13.8 \pm 1.5^{\dagger}$ & $8.3 \pm 1.2^{* * *}, \S$ \\
\hline Testosterone, ng/dl & $42.5 \pm 4.6$ & $28.7 \pm 3.8^{* *, t}$ & $77.5 \pm 7.7^{\dagger}$ & $79.9 \pm 10.0^{* * *}$ \\
\hline Androstendione, $\mathrm{ng} / \mathrm{ml}$ & $1.5 \pm 0.2$ & $1.9 \pm 0.2^{* *}, \hbar$ & $3.8 \pm 0.3^{\dagger}$ & $3.6 \pm 0.2^{* * *}$ \\
\hline DHEA-S, $\mu \mathrm{g} / \mathrm{dl}$ & $156 \pm 19$ & $167 \pm 35^{* *,+}$ & $332 \pm 67^{\dagger}$ & $326 \pm 56^{* * *}$ \\
\hline Fasting glucose, $\mathrm{mg} / \mathrm{dl}$ & $86 \pm 2$ & $83 \pm 4$ & $87 \pm 3$ & $89 \pm 1$ \\
\hline 2-h glucose, mg/dl & $118 \pm 7$ & $117 \pm 3$ & $103 \pm 7$ & $117 \pm 7$ \\
\hline $\mathrm{AUC}_{0-30}$ glucose, $\mathrm{mg} / \mathrm{dl}$ & $3594 \pm 207$ & $3033 \pm 149$ & $3518 \pm 175$ & $3300 \pm 117$ \\
\hline Fasting insulin, $\mu \mathrm{i} \mathrm{U} / \mathrm{ml}$ & $5.9 \pm 1.1$ & $14.0 \pm 2.3^{*}, *$ & $10.6 \pm 1.2$ & $20.3 \pm 3.2^{* * *, \S}$ \\
\hline IS $_{\text {OGTT }}$ & $8.2 \pm 0.7$ & $4.6 \pm 1.3^{*}$ & $5.0 \pm 0.5^{\dagger}$ & $2.9 \pm 0.6^{* * *}$ \\
\hline Fasting IL-6, pg/ml & $0.9 \pm 0.1$ & $2.3 \pm 0.3^{*}$ & $1.4 \pm 0.3$ & $2.2 \pm 0.3^{* * *}$ \\
\hline Fasting CRP, mg/l & $0.2 \pm 0.1$ & $7.2 \pm 0.9^{*}, * *$ & $1.1 \pm 0.3$ & $5.5 \pm 1.3^{* * *}, \S$ \\
\hline Fasting sVCAM-1, ng/ml & $351 \pm 36$ & $379 \pm 14$ & $360 \pm 12$ & $401 \pm 35$ \\
\hline
\end{tabular}

Values are expressed as means \pm SE. Conversion factors to SI units: testosterone $\times 3.467$ (nmol/l), androstenedione $\times 3.492(\mathrm{nmol} / \mathrm{l})$, DHEA-S $\times 0.002714(\mu \mathrm{mol} / \mathrm{l})$, glucose $\times 0.0551(\mathrm{mmol} / \mathrm{l})$, insulin $\times 7.175(\mathrm{pmol} / \mathrm{l})$. $\mathrm{AUC}_{0}-30$ glucose, area under the curve for glucose during the first 30 min of the oral glucose tolerance test (OGTT); ISOGTT, insulin sensitivity derived from the OGTT.

* Obese Control vs. Lean Control, $\mathrm{p}<0.02$

** Obese Control vs. Lean PCOS, p < 0.03

*** Obese PCOS vs. Lean Control, $\mathrm{p}<0.03$

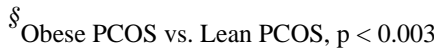

${ }^{\dagger}$ Lean PCOS vs. Lean Control, $\mathrm{p}<0.03$ 
† Obese Control vs. Obese PCOS, p $<0.05$ 